\title{
Mapping trends of large and medium size carnivores of conservation interest in Romania
}

\author{
C. Cazacu, M.C. Adamescu, O. Ionescu, G. Ionescu, R. Jurj, M. Popa, R. Cazacu, \\ A. Coțovelea
}

Cazacu C., Adamescu M.C., Ionescu O., Ionescu G., Jurj R., Popa M., Cazacu

R., Coțovelea A., 2014. Mapping trends of large and medium size carnivores of conservation interest in Romania. Ann. For. Res. 57(1): 97-107, 2014.

Abstract. We analysed yearly estimates of population size data during 20012012 for five carnivores species of conservation interest (Ursus arctos, Canis lupus, Lynx lynx, Felis silvestris and Canis aureus). Population size estimations were done by the game management authorities and integrated by the competent authorities on the Ministry of Environment and Climate Change. Trends in data were detected using non-parametric Mann-Kendall test. This test was chosen considering the short length of data series and its usefulness for non-normal distributed data. The trend was tested at three spatial scales: game management units $(n=1565)$, biogeographical region $(\mathrm{n}=5)$ and national. Trends depicted for each game management unit were plotted using ArcGIS, resulting species trend distribution maps. For the studied period, increasing population trends were observed for Ursus arctos, Canis lupus, Canis aureus and Lynx lynx, while for Felis silvestris there was no trend recorded. The analysis could be especially useful for conservation proposes, game management and reporting obligations under article 17 of the EC Habitat Directive, using population trend as a proxy for population dynamics. We conclude that the status of the five carnivore species is favourable during the study period. Keywords carnivores population trend, game management, Man Kendall statistics, trend detection, GIS.

Authors. Constantin Cazacu (cazacu.constantin@gmail.com), Mihai Cristian Adamescu - Department of Systems Ecology, Bucharest University, Splaiul Independenței 91-95 Sector 5, 76201, Bucharest, Romania; Ovidiu Ionescu, Georgeta Ionescu, Ancuța Coțovelea - Transilvania University, Faculty of Silviculture and Forest Engineering, Department of Silviculture, 1 Beethoven Lane, 500123, Braşov, Romania and Forest Research and Management Institute, 13 Cloşca Street, 500040, Braşov, Romania; Ramon Jurj, Marius Popa, Roxana Cazacu - Forest Research and Management Institute, 13 Cloşca Street, 500040, Braşov, Romania.

Manuscript received January 24, 2014; revised June 01, 2014; accepted June 04, 2014; online first June 05, 2014. 


\section{Introduction}

The ratification of Convention on Conservation of European Wildlife and their Natural Habitats (Bern 1979) led to occurrence of Habitats Directive as European Union's response to obligations arising from it for its member states. The objective and scope of Europe's Habitats Directive is to contribute towards ensuring biodiversity through conservation of natural habitats and species. The Directive applies to more then 1000 species and to about 230 habitats distributed within its member states territories. EU Member States are required to ensure that these species and habitat types are maintained at, or restored to, a 'favourable conservation status'. Most carnivores are listed at least in one of the directive annexes, a fact that imposes special management measures. As the large and medium size carnivores are also important game species, their management was historically related with hunting management.

Therefore, in the last part of the $19^{\text {th }}$ century a land planning system that delineated game management units, known also as "revier system", aimed at conservation and management of game species was introduced throughout Europe (Finch 2010). The hunting area is an area of land that supports a population of game. These areas are a lease or title over the hunting and game rights to the area apart from the land tenure. Such a system proved to be efficient from managerial perspective, since some game population increased even more then system estimated carrying capacity (Almasan 1988, Ionescu 2002, Finch 2010, Jurj et al. 2011, Kaczensky 2013). Game management unit owners/administrators are responsible for estimating game populations sizes, proposing harvest quotas to national competent authorities and keeping harvest records. Also, the well-being of animals within the hunting area is their responsibility otherwise legal penalties may apply for wildlife infringements. Currently in Romania there are a number of 2153 game management units, with surfaces varying between 5090 to $34132 \mathrm{Ha}$, covering $92 \%$ of country surface (INS 2009) (exception being some parts of the Danube Delta).

In order to adapt to a complex reality (i.e. land use change, habitat loos, climate change) a shift from "game management" to "ecosystem management" was done (Feldhamer 2003). This type of management is consistent with the development of conservation and monitoring schemes that should be developed across Europe as a response to the requirements of different Conventions and Directives (Bern Convention, Habitat Directive, Bonn Convention and Convention on Biological Diversity). Across Europe different monitoring schemes were applied for mammal populations initially due to hunting activities and later these were adapted for conservational concerns (Garshelis 1990). Currently the monitoring designs have to cover larger scales, longer times spans and a broad range of variables (Feldhamer 2003) in order cover the complexity.

In 2008 the Large Carnivore Initiative for Europe (LCIE) proposed a common European approach for carnivores management in accordance with requirements of Habitat Directive (Linnell et al. 2008), main important aspect being related with operationalization of "Conservation Status" concept, that should be monitored and maintained "favourable" throughout European Union for species of conservation interest. In order to know the status of conservation as implied by EU Habitat directive, LACIE suggests the following parameters/activities should known or implemented: (i) population trends as measurement of population dynamics, (ii) trends of population distribution as indicator for the range, (iii) knowledge about trends in quality and continuity of habitats, (iv) assuring that population size and range is equal of greater then it was when the directive came into force, (v) reached favorable population size using the IUCN red list criteria $\mathrm{E}$ or $\mathrm{D}$, (vi) the population is occupying the favorable reference range, (vii) the genetic connectivity in- and intra- popula- 
tion is maintained or enhanced, (viii) [robust monitoring programs] of population are implemented (Linnell et al. 2008).

The hunting activities in Romania are currently facing a complex environment, with both conservation and sustainability constrains, as well as with economic (maximizing the profits) and social pressures. Due to this complex situation, together with a variety of pressures from other potential threatening activities like agriculture practices involving the use of pesticides and insecticides which are concentrating on the trophic chains, land use/ landscape changes with direct impact upon the availability and quality of habitat, the mammal species and other species of conservation interest showed a decreasing trend in Europe (Temple \& Terry 2007, Linnell et al. 2008)

An IUCN report (Temple \& Terry 2007, 2009 ) showed that $27 \%$ of mammal populations are in decline, $32 \%$ of the populations are reported as stable and $8 \%$ of species populations are increasing. In the same time there are gaps in knowledge showing that for 33\% of the populations the trend is unknown. In Romania information about the carnivores populations (Almăşan et al. 1963, Jurj et al. 2011, Kaczensky 2013) and their trends have been communicated over the years, usually as numerical fluctuation or based on expert judgment (Ionescu 1993, Ionescu et al. 2000, Jurj et al. 2011, Geacu 2009, 2011, 2012, Ionescu in Kaczensky 2013), but articles proposing methodologies for time series data analysis are lacking.

The aim of this work is to provide a reliable technique aimed at identification and mapping the population trends, of based on available data. This technique was tested for five carnivore species of conservation interest: Ursus arctos, Canis lupus, Lynx lynx, Felis silvestris and Canis aureus as they are listed in at leas one of the EU Habitat Directive annexes. Such an analysis can be used in assisting different decision makers in formulating management strategies, identifying areas that would need intervention in regulating the levels of population to an optimum and is also useful to depict the species conservation status as required by the Article 17 of Habitat Directive.

\section{Materials and methods}

\section{Species of interest}

We focused our study on five species of carnivores: brown bear (Ursus arctos), the grey wolf (Canis lupus), Eurasian lynx (Lynx lynx), wild cat (Felis silvestris) and the golden jackal (Canis aureus). These species are of conservation interest, as being listed on the annexes of EU Habitat Directive. The first four are listed on the annex II and annex IV being species for which Natura 2000 sites should be declared and their conservation status should be maintained as favorable, also they are regarded as species in need of strict protection. The golden jackal, listed on the annex $\mathrm{V}$, is a species of conservation interest for which taking in the wild and exploitation may be subject to management measures.

\section{Datasets}

In Romania, the estimation of the population size for game species is done by game management unit administrations, starting from the end of 50's. Track counts and scat deposition along a transect are the methods generally used to estimate the population size (Beasom 1974a, Crete \& Messier 1987, Palomares et al. 1996, Van Dyke et al. 1986, Van Sickle \& Lindzey 1991, Smallwood \& Fitzhugh 1991, Beier \& Cunningham 1996, Stander 1998). Yearly estimates provided by game management unit administrators are randomly verified in $10 \%$ cases and further corrected, in order to eliminate the overestimates of population sizes as result of double counting of species individuals moving in between different game management units (Jurj et al. 2011). For the current study, 
we used official data for the period 2001-2012 provided by central authority in charge with game management (i.e. Ministry of Environment and Climate Change). The total amount of individual data for the mentioned period consists of over 38000 records. Number of game management units per biogeographical region reporting population estimates of carnivores targeted by this study is summarized in the Table 1.

\section{Data analysis}

Analyses were carried out on three spatial levels: national, biogeographical regions and game management units. In order to identify population trends, Mann-Kendall statistics was used because this statistical procedure being suitable for short time series having cases with monotonous trends and no seasonal or other cycles in the data (Kendall 1970, Gilbert 1987).

The test is based on the difference between consecutive values, then counting the positive and negative values and make difference between them.

$$
S=P-M
$$

where: $\mathrm{S}$ - test score, $P$ positive values and $M$ - negative values.

$\tau$ coefficient is calculated based on the formula:

$$
\tau=\frac{S}{n(n-1) / 2}
$$

where: $n-$ is the number of values in the time series. Null hypothesis is accepted in case of $\tau=0$ and is rejected in case of $\tau$ is different then zero.

In our case, due to the length of time series (greater the 10) and the presence of tied values, calculation of the variance of $\mathrm{S}$ was done following the formula:

$\operatorname{VAR}(S)=\frac{1}{18}\left[n(n-1)(2 n+5)-\sum_{p=1}^{q} t_{p}\left(t_{p}-1\right)\left(t_{p}+5\right)\right]$

where: $q$ is the number of tied groups and $t_{p}$ - number of data values in the $\mathrm{p}^{\text {th }}$ group.

The values of $\mathrm{S}$ and $\operatorname{VAR}(\mathrm{S})$ are used to compute the test statistic $Z$ :

$$
Z= \begin{cases}\frac{S-1}{\sqrt{\operatorname{VAR}(S)}} & \text { if } S>0 \\ 0 & \text { if } S=0 \\ \frac{S+1}{\sqrt{\operatorname{VAR}(S)}} & \text { if } S<0\end{cases}
$$

The presence of a statistically significant trend is evaluated using the $Z$ value. A positive (negative) value of $Z$ indicates an upward (downward) trend. The statistic $Z$ has a normal distribution. To test for either an upward or downward monotone trend (a two-tailed test) at $\alpha$ level of significance, $H_{0}$ is rejected if the absolute value of $Z$ is greater than $Z_{1-\alpha / 2}$, where $Z_{1-\alpha / 2}$ is obtained from the standard normal cumulative distribution tables.

To estimate the true slope of an existing trend (as change per year) the Sen's nonparametric method is used. The Sen's method can be used

Table 1 Number of game management units reporting population estimates for period 2001-2012

\begin{tabular}{llllllr}
\hline Species & \multicolumn{7}{l}{ Number of game management units per biogeographical region } \\
\cline { 2 - 6 } & Alpine & Continental & Pannonic & Steppic & Black Sea & Total \\
\hline Canis aureus & & 83 & 2 & 114 & 4 & 201 \\
Canis lupus & 382 & 414 & 13 & & 811 \\
Felis silvestris & 389 & 850 & & 135 & 3 & 1438 \\
Lynx lynx & 366 & 183 & & & 549 \\
Ursus arctos & 357 & 189 & & & 546 \\
\hline
\end{tabular}


in cases where the trend can be assumed to be linear (Sen 1968).

Two advantages of using this statistical method should be noted: first is that the data doesn't need to conform to any particular distribution and the second, is its low sensitivity to abrupt breaks in case of inhomogeneous time series (Tabari et al. 2011). A positive (negative) value of S indicates an upward (downward) trend (Salmi et al. 2002, Luo et al. 2008).

Statistical analyses were carried out using $\mathrm{R}$ statistical software, package Kendall (McLeod 2013). Data preparation was done using MS Excel for tabular calculations and MS Access for managing data relations.

Trends directions (i.e. increasing, decreasing, no trend) identified for each hunting area were mapped using ArcGIS 9.x, while for upper spatial levels (biogeographical regions and national), tabular forms were used.

\section{Results}

\section{Country and bio-geographical trends}

At national level the Mann-Kendall test revealed significant increasing trends for Canis aureus, Canis lupus, Lynx lynx and Ursus arctos, while no trend was observed for Felis silvestris population (Table 2). Sen's trend lines showing the strength and direction of trend are presented in Figure 1a-e.

Result of analysis at biogeographical region level is summarized in the Table 3.

The Golden jackal populations are mainly distributed in steppic, about $64 \%$ and in con- tinental region with $34 \%$, while in the Black Sea region only $2 \%$ of the population can be found. We can notice that golden jackal has a significant increasing trend in all the three biogeographically regions report which its presence.

Grey wolf has a significant but moderate increase in continental ( $\tau=0.545, p=0.016)$, a consistent increase in alpine region $(\tau=0.818$, $p=0.00028)$ and a significant decrease in steppic region. Grey wolf populations are more evenly distributed between alpine, $60 \%$ and continental, more than 39\% regions.

Wildcat has a stable trend during reported period in all biogeographical regions with the exception of a slightly decreasing trend observed in Pannonian regions $(\tau=-0.534, p=$ $0.01944)$. Anyway, more than $60 \%$ of the Felis silvestris population occurs in continental region and almost $30 \%$ in the alpine region. The remaining of $10 \%$ is shared between the other three biogeographical regions.

The Eurasian lynx is manly distributed within alpine biogeographical region-about $72 \%$, while the rest of $28 \%$ is present in the continental region adjacent to the alpine one. However, a strong increasing trend was noted in the alpine region and a stable trend (i.e. no trend) in the continental.

Most of the brown bear population (78\%) is found in the alpine biogeographic region and only $22 \%$ in continental. A significant increasing trend was observed in both biogeographical regions.

Table 2 Mann-Kendall trends test for five carnivores species of conservation interest at national level

\begin{tabular}{llllll}
\hline Specie & $\mathrm{n}$ & $\mathrm{S}$ & tau & $p$-value (2-sided) & interpretation \\
\hline Canis aureus & 12 & 62 & 0.939 & $2.88 \mathrm{E}-05$ & significant increase \\
Canis lupus & 12 & 52 & 0.788 & 0.0004701 & significant increase \\
Felis silvestris & 12 & -22 & -0.333 & 0.14986 & no trend \\
Lynx lynx & 12 & 53 & 0.809 & $3.51 \mathrm{E}-04$ & significant increase \\
Ursus arctos & 12 & 62 & 0.939 & $2.88 \mathrm{E}-05$ & significant increase \\
\hline
\end{tabular}




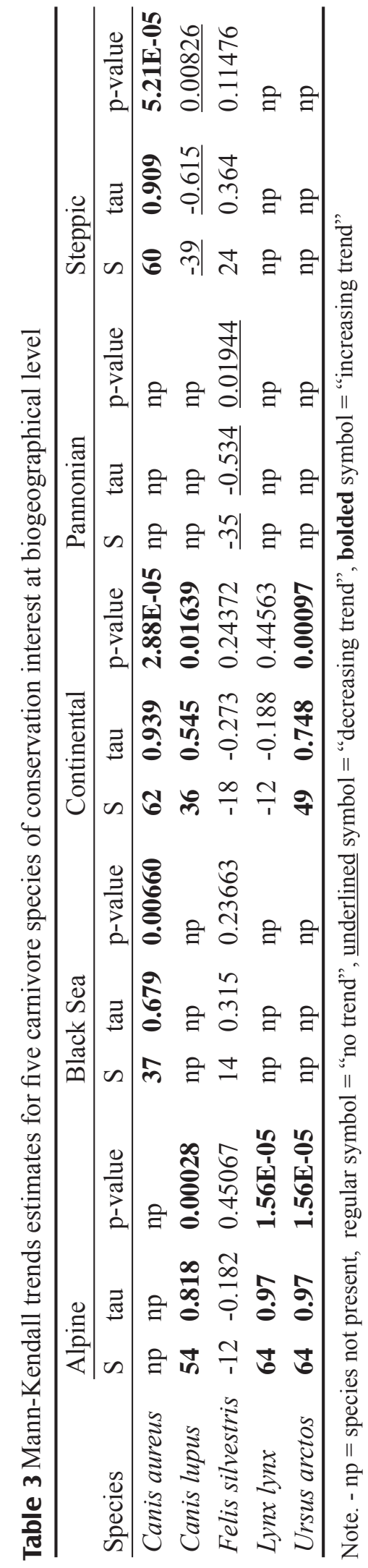

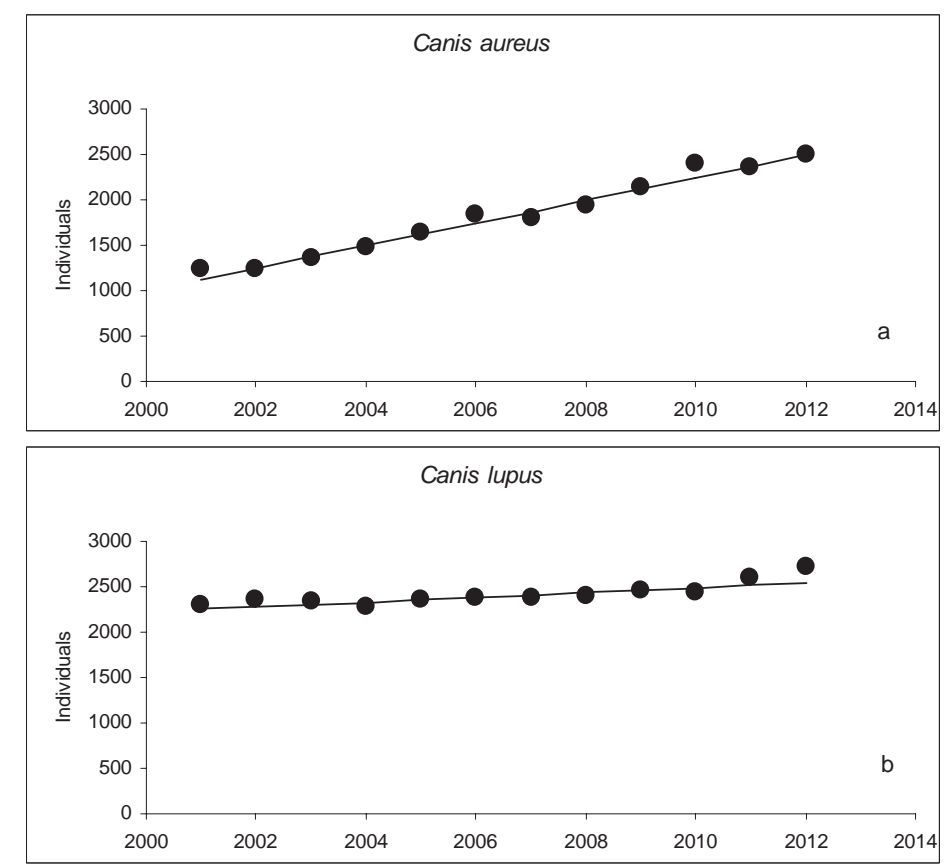
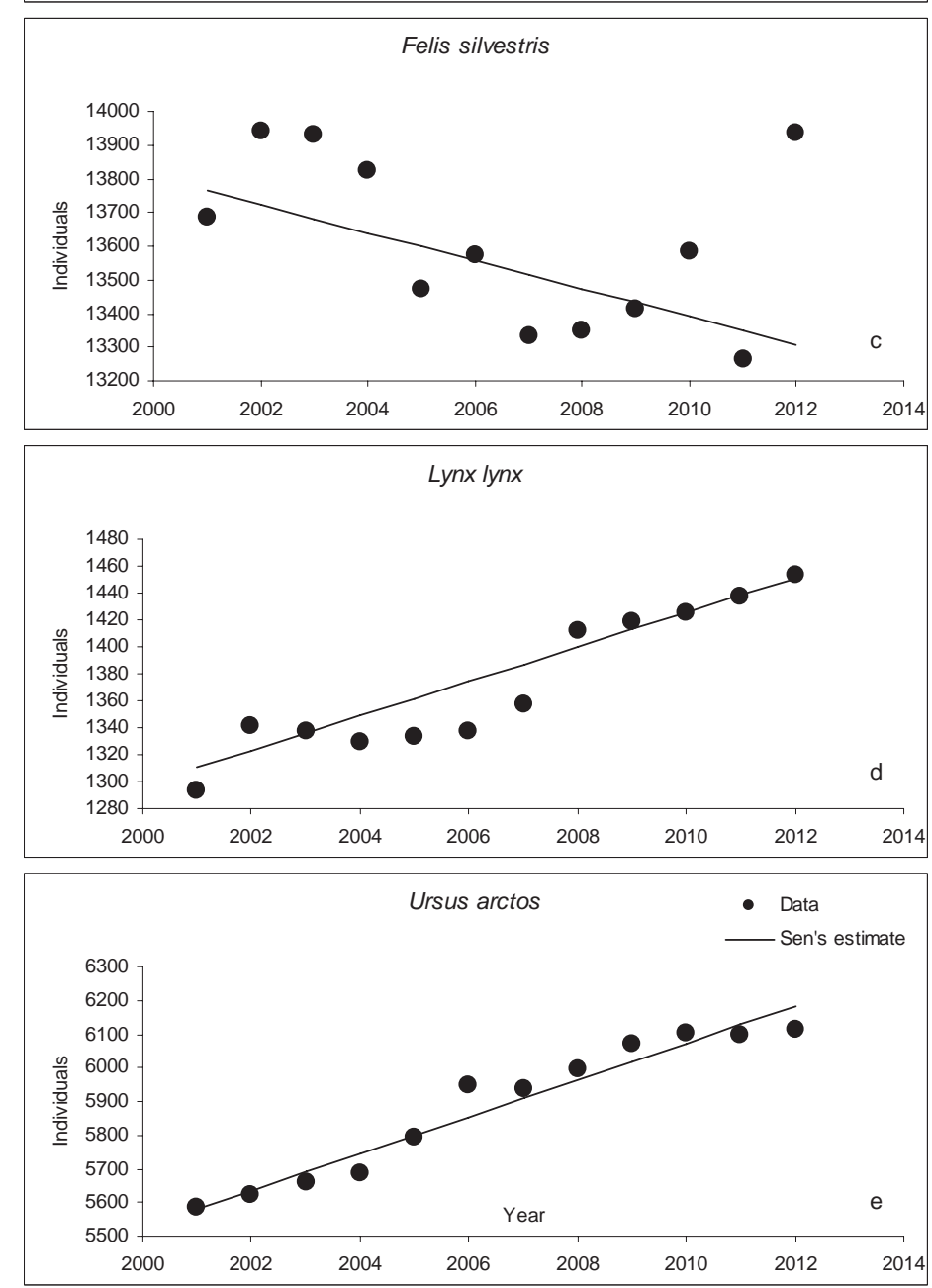

Figure 1 National level Sen's estimates of trends for carnivores' population of conservation interest 


\section{Game management unit level}

Golden jackal (Canis aureus, Linnaeus 1758). The golden jackal populations could be considered as a species in territorial expansion, presenting increasing trends in $55 \%$ of game management units. These game management units are mainly distributed along the Danube River, where golden jackal can find suitable habitats (i.e. reed areas) (Figure 2a).

The Grey wolf (Canis lupus, Linnaeus 1758). Most of the wolf populations are occurring in alpine biogeographical region, about 1451 individuals from a total estimated number of 2419 individuals (eleven years average). The visual analysis of the distribution of trend at game management unit level do not reveal patterns of significant decrease or increase in population trends (Figure 2b). Anyway, some areas that may raise attention by their decreasing trend, even they are not large or compact, could be located in Bucegi and Apuseni mountains and also in the south western areas of Danube gorges.

Wildcat (Felis silvestris, Schreber 1777). From the total number of game management units reporting the presence of wildcat (Table 1), 16\% shows a significant increasing trend, while $15 \%$ presents a significant decreasing trend. Looking at the distribution of trends, we noticed an equilibrated spread of game management units, with increasing and decreasing trends among those with stable trends at country level (Figure 2c).

Eurasian lynx (Lynx lynx, Linnaeus 1758). The Eurasian lynx is reported by 551 game management units (Table 1) from which $20 \%$ shows a significant increasing trend in population, $68 \%$ has no trend and $12 \%$ has a decreasing trend. Looking at the trend distribution map we can distinguish grouped game management units showing a decreasing trend in the Western part of Carpathian Mountains (Figure 2d).

Brown bear (Ursus arctos, Linnaeus 1758). Looking at the map of trend distributions we may notice that game management units with increasing trend are somehow grouped in the central part of Carpathian Mountains in the counties of Covasna, Harghita and Braşov. Also, compact areas of population decreasing trends can be seen in the south-western Carpathians and Apuseni mountains (Figure 2e).

\section{Discussion}

With this study we tested a method for identifying trend in data that is largely used in many sciences areas (Gilbert 1987, Birsan 2005) but rarely in biological sciences (Lento et al. 2012). The Mann-Kendall statistics proved to be a robust and easy to use tool for trend detection in time series like those of population size estimations. Slightly variation in sing and value of the test $(S)$ for this period can be explained by the natural variations of population size without necessarily generating a trend (positive or negative), which is the case of wildcat in our dataset. By combining this technique with mapping, we provided a general picture in of distribution of changes in population dynamics. For instance, the presence of grey wolf population in steppic biogeographical region is considered only marginal, but the presence of individuals was constantly reported during the studied period (Kaczensky 2013). The presence of grey wolf in this region can be explained by migration of some individuals from Bulgaria. However, the significantly decreasing trend of the grey wolf population inhabiting in the steppic biogeographical region was observed (Table 3) and can be explained by habitat conditions that offers limited refuge areas and also by the reduced availability of food. Anyway, looking on map (Figure 2b) the negative trend distribution was isolated to few game management units, most of the trend being stable (i.e. not increasing or decreasing).

The distribution of Golden jackal at European level is in a continuous change due to the long-range dispersal rates (Krystufek et al. 1990, Krystufek et al. 1997, Arnold et al. 


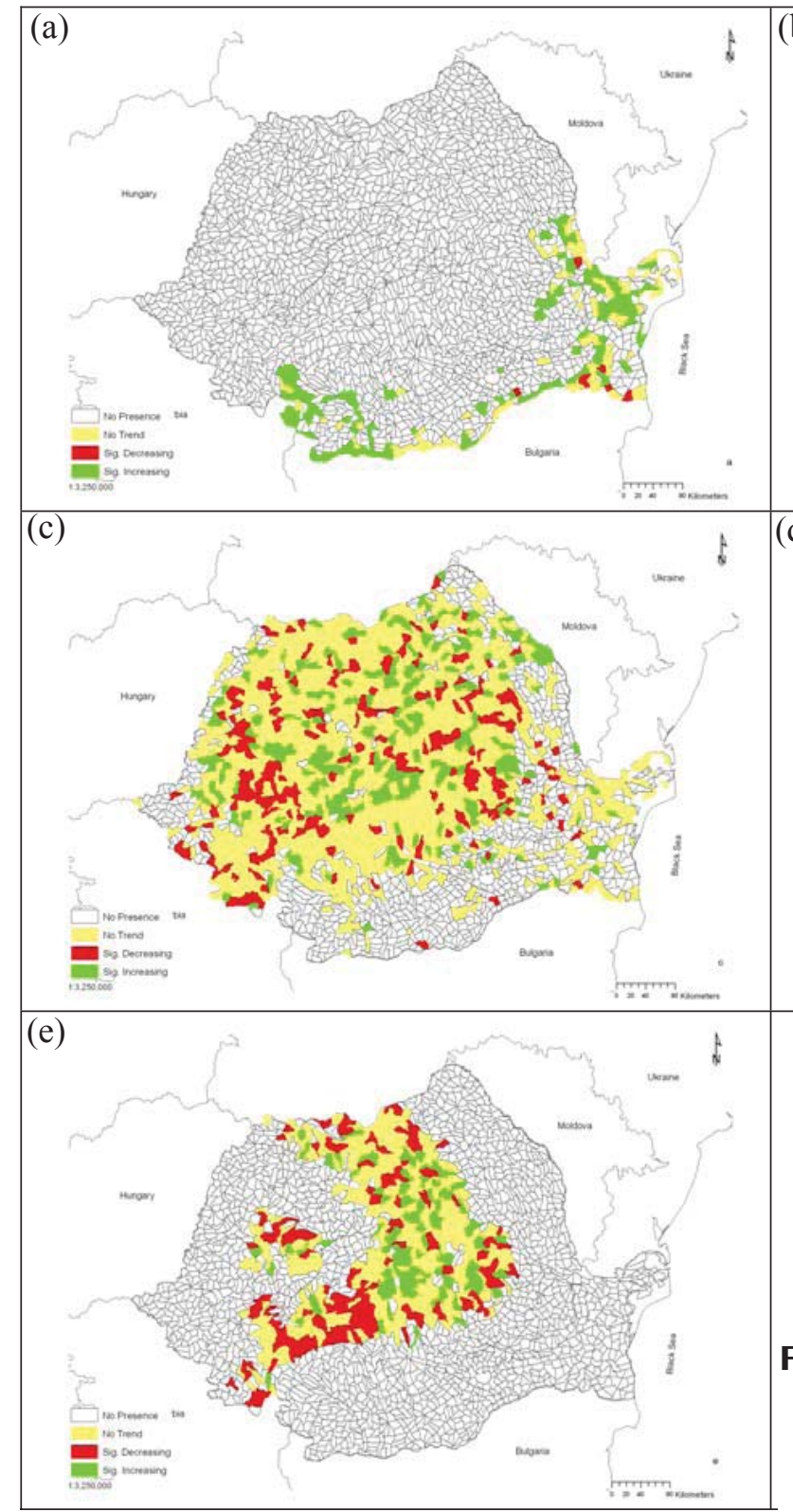

(b)

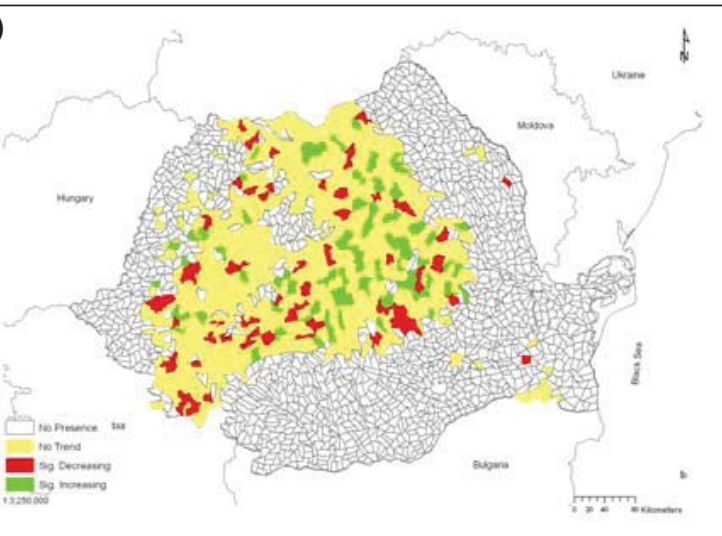

(d)

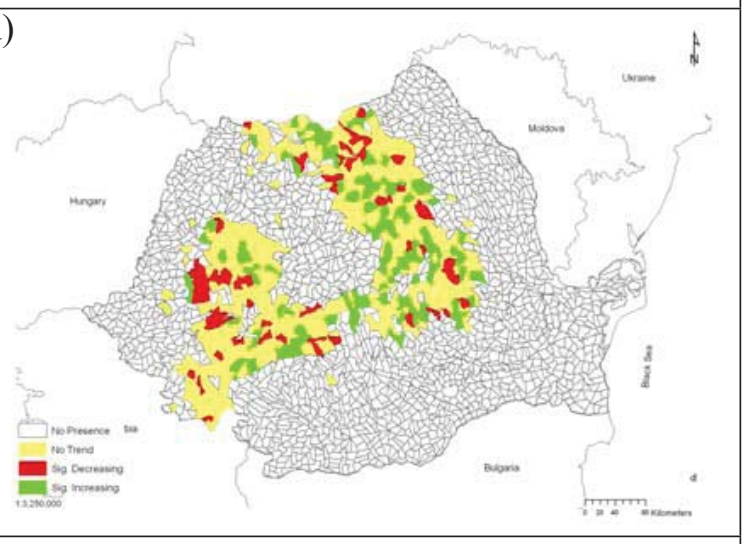

Figure 2 Distribution of population trend at game management units level. (from left to right $\mathrm{a}-$ Canis aureus, $\mathrm{b}-$ Canis lupus, $\mathrm{c}-$ Felis silvetris , $\mathrm{d}-$ Lynx lynx, $\mathrm{e}-$ Ursus arctos)

2011), our analysis, as well by the dominant increasing trend the species has.

Nevertheless, because it is based on data gathered by the hunting authorities, the results should be interpreted with caution. Independent assessments and monitoring schemes should be further implemented, in order to minimize the errors and to assure the objectivity of the datasets. On the other hand, the increasing or no trends observed for game populations at national level should be expected, if will be considered the active management requested by hunting low, which imposie the maintenance of an optimum size of the population per hunting area (Salvatori et al. 2002, Jurj et al. 2011). Considering the trends identified at game management unit as proxies of the population viability and as a measure of conservation status (Linnell et al. 2008), we may leave the door open for further analyses such as hotspots (Rozylowicz et al. 2011, Cogălniceanu et al. 2013), as well as interpretation of the results in the context of "umbrella species" approach, keeping in mind that a large number 
of birds and mammals of conservation interest may benefit from favorable conservation status of carnivores (Rozylowicz et al. 2011).

\section{Conclusions}

Resuming the results, only in case of Felis silvestris at national level, we could not observe a trend. Increasing population trends have been identified for Ursus arctos, Canis lupus, Canis aureus and Lynx lynx.

We assumed that data used in our study is giving an accurate picture of carnivore populations size and trends detected at different spatial levels reflects the reality on the ground and that hunting administrators are sometimes reporting more than the real number of individuals for carnivores due to the bias of methods involved, particularities of the landscape, double counting. The solutions would be in development of a monitoring system with a common database, an integration of the existing data and the use of independent surveyors (i.e. biologists, qualified public - "citizen scientist", photo trapping data etc.) or alternative methods with less bias and better detectability (ex. gene analysis). This work should involve a coherent country wide monitoring design applied for all species of conservation interest, in accordance with Habitat Directive articles 6, 11 and 17 and its further recommendations. Such a monitoring scheme should be aimed not only to estimate the population size, but also their conservation status by taking into account habitat quality and species perspectives, in relation with human activities that potentially affect the presence of species.

\section{Acknowledgements}

This work was supported by the strategic grant POSDRU/89/1.5/S/58852, Project „Postdoctoral programme for training scientific researchers" cofinanced by the European Social
Found within the Sectoral Operational Program Human Resources Development 2007 -2013”. We would also like to thank to anonymous reviewers for their suggestions and comments.

\section{References}

Almăşan H., 1988. Suitability of hunting management units and optimum population size for the main Romania's game species, Forest Research and Management Institute Bucharest [Bonitatea fondurilor de vânătoare şi efectivele optime la principalele specii de vânat din România] ICAS Bucureşti 94-98 pp.

Almăşan H., Popescu C., Andone G., Babuția T., Nițulescu M., Radu Ş., Radu D., Scărlătescu G., 1963. Distribution of game species in Romania. Studies and research vol XXIII-A, Ministry of Forest Economy, Forest Research and Management Institute, Agro-forestry publishing house, Bucharest [Răspândirea speciilor de vânat în R.P.R. Studii şi cercetări, Vol. XXIII-A, Ministerul Economiei Forestiere, Institutul de cercetări forestiere, Editura agro-silvică, Bucureşti].

Anderson J.L., 1981. The re-establishment and management of a lion Panthera leo population in Zululand, South Africa. Biological Conservation 19: 107-117. DOI: 10.1016/0006-3207(81)90046-X.

Beasom S.L., 1974a. Intensive short-term predator removal as a game management tool. Transactions of the North American Wildlife and Natural Resources Conference 39: 230-240.

Beier P., Cunningham S.C., 1996. Power of track surveys to detect changes in cougar populations. Wildlife Society Bulletin 24: 540-546.

Bîrsan M.V., Molnár P., Burlando P., Pfaundler M., 2005. Streamflow trends in Switzerland. Journal of Hydrology 314 pp. 312-329. DOI: 10.1016/j.jhydrol.2005.06.008.

Cazacu C., Adamescu M.C., Ionescu O., Ionescu G., Jurj R., Popa M., Cazacu R., Cotovelea A., 2013. Monitoring conservation status of Natura 2000 medium and large sized terrestrial mammals in Romania, presented in abstract at CZGA. pag 211.

Cogălniceanu D., Rozylowicz L., Székely P., Samoilă C., Stănescu F, Tudor M, Székely D, Iosif R, 2013. Diversity and distribution of reptiles in Romania. Zookeys 341: 49-76. DOI: 10.3897/zookeys.341.5502.

Crete M., Messier F., 1987. Evaluation of indices of gray wolf, Canis lupus, density in hardwood-conifer forests of southwestern Quebec. Canadian Field-Naturalist 101: $147-152$

Feldhamer G.A., Thompson B.C., Chapman J.A., 2003. Wild Mammals of North America: Biology, Management and Conservation, $2^{\text {nd }}$ edition. Johns Hopkins University Press.

Garshelis D.L., Ames J.A., Hardy R.A., Wendell F.E., 
1990. Indices used to assess status of sea otter populations: a comment. Journal of Wildlife Management 54: 260-269. DOI: $10.2307 / 3809039$

Geacu S., 2009. The wolf populations in Romania and the human impact, Rev. Roum. Géogr./Rom. Journ. Geogr. 53(2): 219-231.

Geacu S., 2011. The dynamics of the Cervidae and Bovidae populations in the fauna of Romania. Romanian Academy publishing house, Bucharest, p. 322.

Geacu S., 2012. The Fallow Deer in Romania, Romanian Academy publishing house, Bucharest, p. 387.

Gilbert R.O., 1987. Statistical Methods for Environmental Pollution Monitoring. van Nostrand Rienhold Company, Inc., New York.

INS 2009. Hunting fund in year 2008, Press release no. 146, Romanian National Institute for Statistics. [Fondul cinegetic în anul 2008, Comunicat de presă nr. 146, Institutul Național de Statistică].

Ionescu O., 2002. Eco-Ethology of chamois in Bucegi Mountains. Ph.D. Thesis Transilvania University of Braşov [Eco-Etologia caprei negre în Bucegi. Teză de doctorat la Universitatea Transilvania], Braşov, 200 p.

Ionescu O., 1993. Current status and prospects for the wolf in Romania. In: Wolves in Europe: status and perspectives (eds. C. Promberger, W. Schröder), Munich Wildlife Society, pp. 51-55.

Jurj R., Ionescu O., 2011. study regarding the assessment of large carnivores and wildcat populations from Romania (Ursus arctos, Canis lupus, Lynx lynx end Felis silvestris) in order to keep them in a favorable conservation status and for setting the harvesting quota for strictly protected species during hunting season 2011 - 2012 - final report. [Raport final pentru Studiul privind estimarea populaţiilor de carnivore mari şi pisică sălbatică din România (Ursus arctos, Canis lupus, Lynx lynx şi Felis silvestris) în vederea menținerii într-o stare favorabilă de conservare şi pentru stabilirea numărului de exemplare din speciile strict protejate care se pot recolta în cadrul sezonului de vânătoare 2011-2012]. available at: http://www.mmediu.ro/protectia_naturii/ biodiversitate/carnivore mari/2012-01-16/2012-0116 carnivore mari evaluare 2011 raportcarnivoremari2011.pdf. last accessed: 04.2014.

Kaczensky P., Chapron G., Von Arx M., Huber D., Andrén H., Linnell J., 2013. Status, management and distribution of large carnivores - bear, lynx, wolf and wolverine - in Europe. 272 p.

Kelly M.J., Betsch J., Wultsch C., Mesa B., Scott Mills L., 2012. Noninvasive Sampling for Carnivores. In: Carnivore Ecology and Conservation: A Handbook of Techniques. Boitani \& Powell, editors. Oxford University Press.

Kendall M.G., 1970. Rank correlation methods, 4th ed. Charles Griffin, London.

Krystufek B., Tvrtkovic N., 1990. Range expansion by dalmatian jackal population in the $20^{\text {th }}$ century (Canis aureus Linnaeus, 1758). Folia Zoologica 39(4): 291-29.

Lento J., Dillon P.J., Somers K.M., 2012. Evaluating long-term trends in littoral benthic macroinvertebrate communities of lakes recovering from acid deposition. Environ. Monitoring and Assessment 184: 7175-7187. DOI: 10.1007/s10661-011-2489-5.

Linnell J., Salvatori V., Boitani L., 2008. Guidelines for population level management plans for large carnivores in Europe. A Large Carnivore Initiative for Europe report prepared for the European Commission.

McLeod A.I., 2013. Kendall rank correlation and MannKendall trend test, Package 'Kendall', CRAN R statistical software.

Neal Finch, 2010. The European model of game management, Australian Hunter 26: 94-95.

Okarma H., 2000. Status of carnivores in the Carpathian Ecoregion, p. 36, available at: http://www1.nina.no/ lcie_new/pdf/635012245140517288_OkarmaWWFStatusofLCsinCarpathians.pdf. last accessed: 04.2014.

Palomares F., Ferreras P., Fedriani J.M., Delibes M., 1996. Spatial relationships between Iberian lynx and other carnivores in an area of south-west Spain. Journal of Applied Ecology 33: 5-13. DOI: 10.2307/2405010.

Rozylowicz L., Popescu D.V., Pătroescu M., Chişamera G., 2011. The potential of large carnivores as conservation surrogates in the Romanian Carpathians. Biodiversity and Conservation 20: 561-579. DOI: 10.1007/ s10531-010-9967-x.

Salmi T., Maata A., Antilla P., Ruoho-Airola T., Amnell T. 2002. Detecting trends of annual values of atmospheric pollutants by the Mann-Kendall test and Sen's slope estimates - the Excel template application Makesens. Finnish Meteorological Institute, Helsinki, Finland, 35 pp.

Salvatori V., Okarma H., Ionescu O. Dovhanych, Y., Find'o, S. and Boitani, L., 2002. Hunting legislation in the Carpathian Mountains: implications for the conservation and management of large carnivores. Wildlife Biology 8: 3-10.

Sen P.K., 1968. Estimates of the regression coefficient based on Kendall's tau. Journal of the American Statistical Association. 63: 1379-1389. DOI: 10.1080/01621459. 1968.10480934.

Sillero-Zubiri C., Laurenson K.M., 2001. Interactions between carnivores and local communities: conflicts or co-existence? In: Gittleman J.L., Funk S.M., Macdonald D. et al. (eds) Carnivore conservation, vol 5 carnivore biology. Cambridge University Press, Cambridge.

Smallwood K.S., Ftzhugh E.L., 1991. The use of track counts for mountain lion population census. Mountain lion- human interaction, Symposium and workshop, Colorado Division of Wildlife, 59-67.

Stander P.E., 1998. Spoor counts as indices of large carnivore populations: the relationship between spoor frequency., sampling effort and true density. Journal of Applied Ecology 35: 378-385. DOI: 10.1046/j.13652664.1998.00313.x.

Tabari H., Marofi S., Ahmadi M., 2011. Longterm variations of water quality parametersin the Maroon River, Iran. Environmental Monitoring and Assessment, 177: 273-287. DOI: 10.1007/s10661-010-1633-y. 
Temple H.J., Terry A., 2009. European mammals: Red List status, trends, and conservation priorities, Folia Zoologica 58(3): 248-269.

Temple H.J., Terry A., 2007. The Status and Distribution of European Mammals. Luxembourg: Office for Official Publications of the European Communities.

Van Dyke F.G., Brocke R.H., Shaw H.G., Ackerman B.B., Hernke T.P., Lindzey F.G., 1986. Reactions of mountain lions to logging and human activity. Journal of Wildlife
Management 50: 95-102. DOI: 10.2307/3801496.

Van Sickle W.D., Lindzey F.G., 1991. Evaluation of a cougar population estimator based on probability sampling. Journal of Wildlife Management 55: 738-743. DOI: $10.2307 / 3809526$.

Yu Y.S., Zou S., Whittemore D., 1993. Non-parametric trend analysis of water quality data of rivers in Kansas. Journal of Hydrology 150: 61-80. DOI: 10.1016/00221694(93)90156-4. 